\title{
Vacuum-assisted closure device for the management of infected postpneumonectomy chest cavities
}

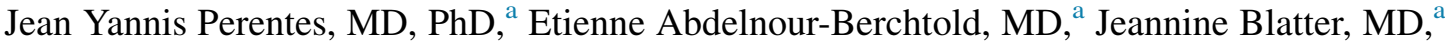 \\ Alban Lovis, MD, ${ }^{\mathrm{b}}$ Hans-Beat Ris, MD, ${ }^{\mathrm{a}}$ Thorsten Krueger, MD, ${ }^{\mathrm{a}}$ and Michel Gonzalez, MD ${ }^{\mathrm{a}}$
}

\begin{abstract}
Background: Infected postpneumonectomy chest cavities may be related to chronic postpneumonectomy empyema or arise in rare situations of necrotizing pneumonia with complete lung destruction where pneumonectomy and pleural debridement are required. We evaluated the safety and efficacy of an intrathoracic vacuum-assisted closure device (VAC) for the treatment of infected postpneumonectomy chest cavities.
\end{abstract}

Method: A retrospective single institution review of all patients with infected postpneumonectomy chest cavities treated by VAC between 2005 and 2013. Patients underwent surgical debridement of the thoracic cavity, muscle flap closure of the bronchial stump when a fistula was present, and repeated intrathoracic VAC dressings until granulation tissue covered the entire chest cavity. After this, the cavity was obliterated by a Clagett procedure and closed.

Results: Twenty-one patients (14 men and 7 women) underwent VAC treatment of their infected postpneumonectomy chest cavity. Twelve patients presented with a chronic postpneumonectomy empyema (10 of them with a bronchopleural fistula) and 9 patients with an empyema occurring in the context of necrotizing pneumonia treated by pneumonectomy. In-hospital mortality was $23 \%$. The median duration of VAC therapy was 23 days (range, 4-61 days) and the median number of VAC changes per patient was 6 (range, 2-14 days). Infection control and successful chest cavity closure was achieved in all surviving patients. One adverse VAC treatment-related event was identified (5\%).

Conclusions: The intrathoracic VAC application is a safe and efficient treatment of infected postpneumonectomy chest cavities and allows the preservation of chest wall integrity. (J Thorac Cardiovasc Surg 2015;149:745-50)

See related commentary on page 751 .

Infected postpneumonectomy chest cavities may occur in the context of a chronic postpneumonectomy empyema or in rare situations of necrotizing pneumonia with complete lung destruction that require pneumonectomy. In both situations, chest cavity infection control is challenging. It is often achieved by the creation of a temporary thoracic window through which gauze packing is performed with repeated dressing changes until granulation tissue covers the chest cavity. To accelerate the healing process, various techniques have been reported. One technique consists of the application of povidone-iodine-soaked towels throughout the chest cavity with negative pressure

\footnotetext{
From the Divisions of Thoracic Surgery ${ }^{\mathrm{a}}$ and Pneumology, ${ }^{\mathrm{b}}$ Centre Hospitalier Universitaire Vaudois, Lausanne, Switzerland.

Disclosures: Authors have nothing to disclose with regard to commercial support.

J.Y.P., E.A.-B., T.K., and M.G. contributed equally to this work.

Received for publication June 14, 2014; revisions received Sept 3, 2014; accepted for publication Oct 6, 2014; available ahead of print Nov 5, 2014.

Address for reprints: Michel Gonzalez, MD, Division of Thoracic Surgery, Centre

Hospitalier Universitaire Vaudois, Rue du Bugnon 46, 1011 Lausanne, Switzerland

(E-mail: Michel.Gonzalez@chuv.ch).

$0022-5223 / \$ 36.00$

Copyright (C) 2015 by The American Association for Thoracic Surgery

http://dx.doi.org/10.1016/j.jtcvs.2014.10.052
}

through chest tubes. This technique was demonstrated to decrease the time necessary for intrathoracic infection control. ${ }^{1,2}$ More recently, negative pressure wound therapy application using a vacuum-assisted closure (VAC) device was shown to facilitate the healing of acute or chronic infection and is currently validated for the management of wounds in various areas of the body, including the chest cavity. ${ }^{3-10}$ This strategy has been shown to promote wound healing through different mechanisms, including accelerated granulation tissue formation, decreased wound bacterial load, removal of excessive interstitial fluid, improvement of tissue oxygenation, and wound volume reduction. ${ }^{11}$

We recently published a study where 27 consecutive patients with severe intrathoracic infections of various etiologies were managed by intrathoracic VAC therapy. ${ }^{12}$ We found that VAC therapy was efficient to control intrathoracic infections and allowed us to preserve chest wall integrity. ${ }^{12}$ Patient acceptance of VAC therapy was good with fewer dressing changes and an accelerated recovery. Other groups have applied the VAC device for the treatment of chronically infected chest cavities and spaces and have endorsed our findings. ${ }^{13-17}$ However, the application of VAC devices for the treatment of infected postpneumonectomy chest cavities has been reported only occasionally and some concerns have been expressed 


\section{Abbreviations and Acronyms \\ $\mathrm{VAC}=$ vacuum-assisted closure \\ $\mathrm{BPF}=$ bronchopleural fistula}

regarding its safety for this specific indication. ${ }^{17,18}$ Here we report a consecutive case series of 21 patients with infected postpneumonectomy chest cavities who were managed by VAC therapy.

\section{MATERIALS AND METHODS}

We retrospectively reviewed the medical records of all patients who were treated for infected postpneumonectomy chest cavities by intrathoracic VAC therapy between January 2005 and December 2013. The study was reviewed and approved by our institution's ethics committee and individual patient consent was waived.

For each patient, we recorded and analyzed the following parameters: age, gender, comorbidities, side and indication for pneumonectomy, the presence of neoadjuvant and adjuvant chemotherapy or radiochemotherapy, and the presence or absence of bronchopleural fistula (BPF). For each patient, overall postoperative morbidity and mortality were noted as well as the duration of VAC therapy, microbiologic analysis of the chest cavity, and time to definitive chest wall closure with hospital length of stay. The patients were grouped according to the underlying cause of VAC treatment: those with a chronic postpneumonectomy empyema, and those with an empyema in the context of a destroyed lung or necrotizing pneumonia requiring pneumonectomy.

For patients with chronic postpneumonectomy empyema, the surgical management before VAC application was adapted according to the presence or absence of a BPF. In presence of a BPF, a rethoracotomy was performed, followed by the debridement of the chest cavity. The bronchial stump and the carina were dissected and debrided. The bronchial stump was closed by circumferential suturing of an extrathoracic muscle flap (serratus anterior or pectoralis anterior muscle flap) into the debrided stump as previously described. ${ }^{19,20}$ In the absence of BPF, debridement of the chest cavity and chest wall was performed before VAC application. In situations of empyema associated to destroyed lungs or necrotizing pneumonia requiring pneumonectomy, bronchial stump and mediastinal reinforcement were obtained by the transposition of extrathoracic muscle flaps followed by the application of a VAC device. In cases where postpneumonectomy empyema was related to a bronchoesophageal fistula that had contaminated a pneumonectomy cavity, the fistula was identified and a serratus anterior muscle was transposed in the chest cavity to close the tracheal defect and separate it from the esophagus. The VAC was then applied in the chest cavity to stabilize the muscle flap on the trachea.

Finally, in the cases where postpneumonectomy empyema occurred in association with necrotizing pneumonia (ie, postlobectomy patients who developed necrotizing pneumonia of their remaining lobe or whole lung necrotizing pneumonias), surgical management consisted of completion pneumonectomy or direct pneumonectomy followed by VAC application in the chest cavity. Because of the massive inflammatory reaction and major risk of developing fistulas, a latissimus dorsi or serratus anterior (in cases of previous thoracotomies) was transposed inside the thoracic cavity to cover the bronchial stump. In all cases, VAC dressing was directly applied in the thoracic cavity after surgery.

In all cases, VAC dressing (KCI Inc, San Antonio, Tex) was applied in the thoracic cavity after surgical debridement and packing of the cavity with sterile dry gauzes (Figure 1, $A$ ) to avoid direct contact of the VAC device with the mediastinum. Polyurethane foam of $20 \times 15 \mathrm{~cm}$ was then applied within the chest cavity overlying the gauzes that usually filled the chest cavity and 1 suction tube was sutured onto this foam (Figure 1, B). These dry gauzes were applied on the mediastinum because they were less difficult to remove in comparison to the black VAC foam and allowed proper drainage of the pleural cavity. A second foam was then placed within the chest wall defect of a 6 to $8 \mathrm{~cm}$ open thoracic window (Figure 1, C). The skin of the thoracotomy incision was closed by interrupted sutures except around the thoracostomy site (Figure 1,C) where a third foam was placed and covered by adhesive tape with the application of a second suction tube (Figure 1,D). As the VAC was producing negative pressure, no chest tubes were inserted. Both suction tubes were connected together to the vacuum pump and negative pressure, ranging from -50 to $-75 \mathrm{~mm} \mathrm{Hg}$, was applied. Patients were maintained under general anesthesia when the negative pressure was applied on the VAC foam: in particular, we measured central venous and systemic blood pressure changes to identify potential hemodynamic changes related to mediastinal compression or shift. These were corrected before patient extubation.

The subsequent VAC dressings were systematically performed under general anesthesia. The skin was partly reopened and the intrathoracic dressing was removed through the thoracostomy. At the end of each procedure, the skin was closed leaving only the small area of pleurostomy covered with a foam to avoid scarring and edge retraction. The first VAC dressing change was generally performed 48 postoperatively and then twice a week until the healing process covers the mediastinum and the chest cavity with granulation tissue. At that time point, pleural space was then obliterated with antibiotic solution and chest wall closed in several layers. Microbiologic analysis was performed at each VAC change by sending the deepest foam for analysis. All patients were initially treated with wide-spectrum antibiotics with adjustment of antimicrobial therapy according to the microbiologic analysis for the time of VAC therapy and antibiotics were stopped 2 weeks after chest wall closure.

Follow-up in surviving patients consisted of a minimum of 3 months per patient, which is the standard postoperative follow-up period in our department.

\section{RESULTS}

Twenty-one patients were managed with an intrathoracic VAC device for infected postpneumonectomy cavities between January 2005 and December 2013. There were 14 men and 7 women. The median age of patients was 66 years (range, 32-77 years). Patient characteristics, comorbidities, and anesthesia risk score (according to the American Society of Anesthesiologists) are summarized in Table 1. Right- and left-sided treatments were performed in $14(66 \%)$ and 7 patients (34\%), respectively.

Twelve patients presented with a chronic postpneumonectomy empyema and associated in 10 of them with a BPF. The indication for pneumonectomy was non-small cell lung cancer $(\mathrm{n}=7)$, Masaoka IV thymic tumors $(\mathrm{n}=2)$, adenoid cystic tumor $(\mathrm{n}=1)$, and mesothelioma $(\mathrm{n}=2)$. In 9 patients, pleural empyema preceded pneumonectomy, which was performed in the context of a necrotizing pneumonia with a destroyed lung following lobectomy for lung cancer $(\mathrm{n}=7)$, lung transplantation $(\mathrm{n}=1)$, and whole lung necrotizing pneumonia $(\mathrm{n}=1)$. Five patients had undergone neoadjuvant chemotherapy for N2 disease, whereas 4 patients had extensive pleural resection in association to pneumonectomy (9 of 21 patients; $42 \%$ ). Microbiologic analyses of the chest cavity before VAC therapy revealed a bacterial or fungal infection 

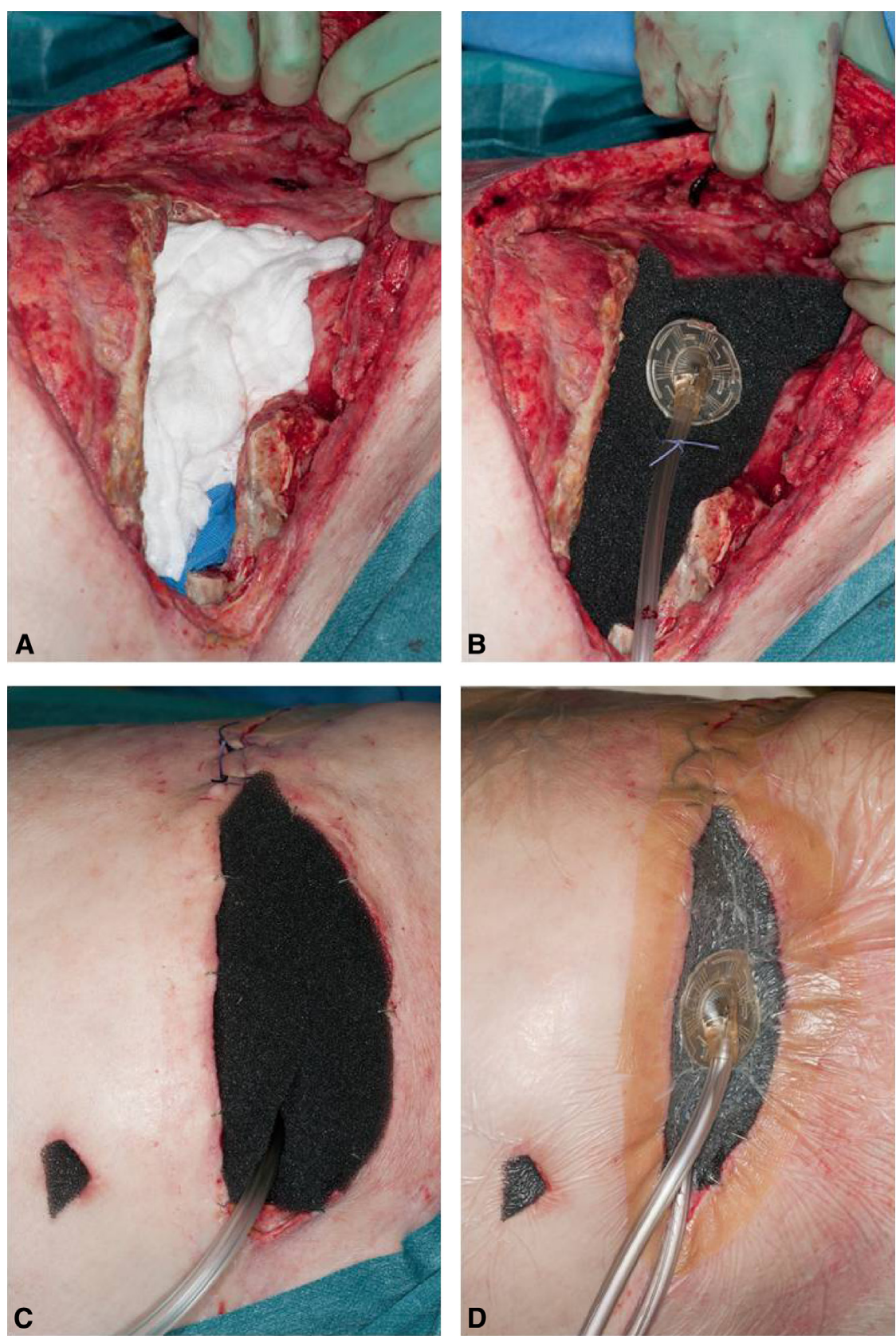

FIGURE 1. Application of the vacuum-assisted closure (VAC) therapy device under general anesthesia. A, Packing of the chest cavity with dry gauzes to avoid direct contact of the VAC device with the mediastinum. B, Polyurethane foam of $20 \times 15 \mathrm{~cm}$ is applied within the chest cavity overlying the gauzes and 1 suction tube is sutured onto this foam. $\mathrm{C}$, A second foam piece is placed within the chest wall defect of a 6 to $8 \mathrm{~cm}$ open thoracic window. D, The skin of the thoracotomy incision is adapted by interrupted sutures except the pleurostomy site where a third foam is placed and covered by adhesive tape with the application of a second suction tube (negative pressure ranging from -50 to $-75 \mathrm{~mm} \mathrm{Hg}$ ).

in 19 patients $(90 \%)$ (Table 2). At time of the definitive chest closure, negative microbiologic cultures were observed in 10 of 19 patients $(53 \%)$. In some cases, bacterial infection had shifted toward nonpathogenic strains that were related to the VAC device contamination (open wound device), whereas other cases had persistent low levels of initial pathogenic strains.
Five patients died within 90 days after the initiation of VAC therapy (90-day mortality of $23 \%$ ). None of the deaths could be attributed to a complication of the VAC therapy. One patient died from pulmonary embolism despite thromboembolic prophylaxis during VAC therapy and before closure of the chest wall. Four other patients died after successful chest wall closure from massive 
TABLE 1. Demographic characteristics and comorbidities of 21 patients undergoing vacuum-assisted closure therapy for infected postpneumonectomy chest cavities

\begin{tabular}{lc}
\hline \multicolumn{1}{c}{ Characteristic/comorbidity } & Result \\
\hline Age, y & $66(32-77)$ \\
Female/male & $7 / 14$ \\
American Society of Anesthesiologists risk score & \\
II & 7 \\
III & 11 \\
IV & 3 \\
Coronary artery disease & 6 \\
Atrial fibrillation & 3 \\
Cerebrovascular accident & 2 \\
Arterial hypertension & 7 \\
Diabetes mellitus & 5 \\
Obesity & 4 \\
Chronic obstructive pulmonary disease & 8 \\
Alcoholism & 3 \\
Malnutrition & 5 \\
Patients with multiple comorbidities $(>3)$ & 12 \\
\hline Valus presen
\end{tabular}

Values are presented as median (range) or $\mathrm{n}$.

bronchoaspiration $(\mathrm{n}=2)$, pulmonary embolism $(\mathrm{n}=1)$, or adult respiratory distress syndrome following pneumonia $(\mathrm{n}=1)$ after chest wall closure. In the surviving patients $(\mathrm{n}=16)$, overall in-hospital morbidity was $83 \%$ and consisted of pneumonia $(\mathrm{n}=9)$, atrial fibrillation $(\mathrm{n}=8)$, nonfatal pulmonary embolism $(n=2)$, colitis $(n=2)$, and myocardial infarction $(\mathrm{n}=1)$.

Overall, the mean duration of VAC therapy was 23 days, ranging from 4 to 61 days (Table 3 ). The median number of VAC changes was 6 (range, 2-14 changes), and the mean interval between VAC changes was $3.8 \pm 0.3$ days. Successful closure of the chest wall was obtained in 19 out of 21 patients $(90 \%)$. One patient died from pulmonary embolism before chest wall closure and 1 patient underwent reoperation and repeat VAC treatment for recurrent infection followed by successful definitive chest wall closure. In 1 case, a complication was related to VAC therapy and consisted of bleeding from the mammary

TABLE 2. Microbiology of the pleural cavity in 21 patients undergoing vacuum-assisted closure (VAC) therapy for infected postpneumonectomy cavities. Six patients had polymicrobial contamination

\begin{tabular}{lr}
\hline \multicolumn{1}{c}{ Microbiology result } & $\mathbf{n}$ \\
\hline Patients with positive cultures & 19 \\
Staphylococcus & 15 \\
Enterococcus & 7 \\
Streptococcus & 2 \\
Pseudomonas aeruginosa & 3 \\
Klebsiella species & 1 \\
Serriata species & 2 \\
Candida species & 5 \\
Aspergillus fumigatus & 3 \\
\hline
\end{tabular}

vein after VAC foam replacement requiring hemostasis (VAC therapy-related complication rate, $5 \%$ ).

\section{DISCUSSION}

An infected postpneumonectomy cavity is a challenging treatment condition that is associated with a mortality of up to $30 \% .^{21,22}$ Its management includes closure of a BPF if present, debridement of the cavity, and management of an infected empty chest cavity while avoiding serious complications such as hemorrhage and injuries of vessels or mediastinal structures. In addition, this condition is often encountered in fragile patients with multiple comorbidities requiring ventilatory support who are at increased risk for the development of various other life-threatening conditions during the perioperative phase. Most studies report mortality in up to $30 \%$ of patients. ${ }^{21,23}$ We have now reported a similar mortality rate $(20 \%)$, which was mainly related to the critical general conditions of the patients rather than to the VAC dressing treatment itself.

Here we report the use of VAC therapy as an adjunct to the traditional surgical approach of infected postpneumonectomy cavities. The surgical strategy for the treatment of chronic postpneumonectomy empyema was adapted according to the procedure initially described by Pairolero and colleagues ${ }^{24}$ with debridement of the chest cavity, closure of an associated BPF by an extrathoracic muscle flap transposed inside the cavity, packing of the chest cavity, and repeated dressing changes through a temporary thoracostomy window. In case of empyema in the context of a destroyed lung or necrotizing pneumonia requiring pneumonectomy, mediastinal reinforcement was achieved by the transposition of an extrathoracic muscle flap transposed in the cavity before packing and VAC application. In both cases, following chest cavity covering by granulation tissue, we filled the pleural cavity with antibiotic fluid and closed the chest. We believe that mediastinal and bronchial stump reinforcement by pedicled muscle flaps is an essential step for successful treatment and closure of infected postpneumonectomy cavities.

Our results indicate that the VAC is safe (1 VAC-related complication), well tolerated, and efficient to control infection and to obtain chest wall closure over a relatively short period of time (23 days) while maintaining chest wall integrity. Our results also show important morbidity and mortality in this population that was not attributable to VAC therapy.

VAC devices are currently widely used for wound closure assistance in virtually all areas of the body. ${ }^{25}$ In the pleural cavity, Varker and colleagues $^{16}$ described the first successful management of a postresectional empyema by VAC in 2006. This was followed by a series of reports that confirmed the usefulness of this device in the treatment of chronically infected residual spaces within the chest 
TABLE 3. Patient outline

\begin{tabular}{|c|c|c|c|c|c|c|c|c|c|c|c|}
\hline Patient no. & Sex & Age & Pathology & Side & BPF & $\begin{array}{c}\text { Necrotic } \\
\text { pneumonia }\end{array}$ & $\begin{array}{l}\text { VAC } \\
\text { days }\end{array}$ & $\begin{array}{c}\text { VAC } \\
\text { changes }\end{array}$ & $\begin{array}{l}\text { Hosp } \\
\text { stay }\end{array}$ & Closure & Complications \\
\hline 1 & M & 67 & NSCLC & Right & Y & $\mathrm{N}$ & 41 & 14 & 45 & $\mathrm{Y}$ & $\mathrm{N}$ \\
\hline 2 & M & 58 & Thymoma & Left & Y & $\mathrm{N}$ & 30 & 8 & 45 & $\mathrm{Y}$ & $\mathrm{N}$ \\
\hline 3 & M & 65 & NSCLC & Right & $\mathrm{N}$ & $\mathrm{Y}$ & 27 & 7 & 44 & $\mathrm{Y}$ & $\mathrm{N}$ \\
\hline 4 & M & 64 & Mesothelioma & Right & Y & $\mathrm{N}$ & 44 & 10 & 72 & $\mathrm{Y}$ & $\mathrm{Y}(\mathrm{BA})$ \\
\hline 5 & M & 62 & Lung transplant & Left & $\mathrm{N}$ & $\mathrm{Y}$ & 22 & 4 & 69 & Y & $\mathrm{Y}(\mathrm{PAT})$ \\
\hline 6 & M & 67 & Pneumonia & Left & $\mathrm{N}$ & $\mathrm{Y}$ & 24 & 6 & 42 & $\mathrm{Y}$ & $\mathrm{N}$ \\
\hline 7 & $\mathrm{~F}$ & 75 & Tuberculosis & Left & $\mathrm{N}$ & $\mathrm{Y}$ & 23 & 7 & 29 & Y & $\mathrm{N}$ \\
\hline 8 & $\mathrm{~F}$ & 77 & NSCLC & Left & $\mathrm{N}$ & $\mathrm{Y}$ & 7 & 3 & 31 & $\mathrm{Y}$ & $\mathrm{Y}(\mathrm{BA})$ \\
\hline 9 & M & 65 & NSCLC & Right & $\mathrm{N}$ & $\mathrm{Y}$ & 10 & 3 & 73 & $\mathrm{~N}$ & Y (ARDS) \\
\hline 10 & $\mathrm{~F}$ & 60 & Thymoma & Right & $\mathrm{Y}$ & $\mathrm{N}$ & 41 & 7 & 160 & $\mathrm{Y}$ & $\mathrm{N}$ \\
\hline 11 & M & 64 & NSCLC & Right & $\mathrm{N}$ & $\mathrm{Y}$ & 19 & 3 & 23 & $\mathrm{Y}$ & $\mathrm{N}$ \\
\hline 12 & M & 73 & NSCLC & Right & $\mathrm{Y}$ & $\mathrm{N}$ & 61 & 10 & 156 & $\mathrm{Y}$ & $\mathrm{N}$ \\
\hline 13 & M & 54 & NSCLC & Left & $\mathrm{N}$ & $\mathrm{Y}$ & 12 & 3 & 3 & $\mathrm{Y}$ & $\mathrm{N}$ \\
\hline 14 & M & 66 & NSCLC & Right & $\mathrm{Y}$ & $\mathrm{N}$ & 22 & 6 & 65 & $\mathrm{Y}$ & $\mathrm{N}$ \\
\hline 15 & $\mathrm{~F}$ & 67 & NSCLC & Right & Y & $\mathrm{N}$ & 49 & 9 & 93 & Y & $\mathrm{N}$ \\
\hline 16 & M & 66 & NSCLC & Right & $\mathrm{Y}$ & $\mathrm{N}$ & 30 & 4 & 55 & $\mathrm{Y}$ & $\mathrm{N}$ \\
\hline 17 & $\mathrm{~F}$ & 63 & Mesothelioma & Left & $\mathrm{N}$ & $\mathrm{N}^{2}$ & 15 & 4 & 22 & $\mathrm{Y}$ & $\mathrm{N}$ \\
\hline 18 & M & 68 & NSCLC & Right & $\mathrm{Y}$ & $\mathrm{N}$ & 4 & 2 & 4 & $\mathrm{~N}$ & Y (PAT) \\
\hline 19 & M & 68 & NSCLC & Right & $\mathrm{Y}$ & $\mathrm{N}$ & 14 & 3 & 18 & $\mathrm{Y}$ & $\mathrm{N}$ \\
\hline 20 & $\mathrm{~F}$ & 75 & NSCLC & Right & $\mathrm{N}$ & $\mathrm{Y}$ & 21 & 3 & 44 & $\mathrm{Y}$ & $\mathrm{N}$ \\
\hline 21 & $\mathrm{~F}$ & 32 & $\mathrm{AC}$ & Right & $\mathrm{N}$ & $\mathrm{N}^{2}$ & 47 & 7 & 213 & $\mathrm{Y}$ & $\mathrm{N}$ \\
\hline $\begin{array}{c}\text { Mean } \pm \text { standard } \\
\text { deviation or } n\end{array}$ & $14 \mathrm{M} / 7 \mathrm{~F}$ & $64 \pm 9$ & NA & $14 \mathrm{R} / 7 \mathrm{~F}$ & 10 & 9 & $26 \pm 15$ & $6 \pm 3$ & $62 \pm 53$ & 19 & 5 \\
\hline
\end{tabular}

$\overline{B P F}$, Bronchopleural fistula (or a necrotizing pneumonia); $V A C$, vacuum-assisted closure; $M$, male; $N S C L C$, non-small cell lung cancer; $Y$, yes; $N$, no; $B A$, bronchoaspiration; $P A T$, pulmonary artery thrombosis; $F$, female; $A R D S$, adult respiratory distress syndrome; $A C$, adenoid cystic carcinoma; $N A$, not applicable.

cavity, with and without previous resections. ${ }^{3,5-7} \mathrm{We}$ recently reported our experience with 27 consecutive patients with intrathoracic infections managed by VAC. ${ }^{12}$ We found this system was a positive adjunct to surgery, that patient satisfaction was high, and that negative pressure appeared to assist with obliteration of residual space. ${ }^{12}$ However, in the context of postpneumonectomy empyema, the adjunct of this device is only sparsely reported. In this context, some specific elements must be considered, including mediastinal stability, infection control of an empty pleural cavity, and tolerance of therapy. Our results indicate that this device did not cause mediastinal shifts with major hemodynamic instabilities. Moreover, infection control was obtained in combination with muscle flap coverage when necessary and antibiotics. Finally, VAC devices allow chest wall closure without affecting chest wall integrity.

Currently, the standard management of infected postpneumonectomy cavities includes open window thoracostomy and repeated gauze dressing changes until coverage of the chest cavity by granulation tissue. However this procedure is cumbersome for patients and staff and requires frequent dressing changes and prolonged hospital stay. ${ }^{26}$ As a consequence, methods to improve speed of chest cavity healing have been developed. Schneiter and colleagues ${ }^{1,2}$ suggested a negative pressure wound therapy system to accelerate the healing process of chronically infected postpneumonectomy cavities. After pleural debridement and BPF closure, the chest wall cavity is packed with dressings of poviodine-iodine and continuous suction of $5 \mathrm{~mm} \mathrm{Hg}$ is then applied through chest tubes left in the pleural cavity. This method showed an efficiency of $94 \%$ and a mortality of $4 \%$ at 90 days after a mean treatment time of 8 days. Whereas these results were very impressive, $13 \%$ of patients required a second treatment cycle for definitive closure of the chest wall. Our results indicated a longer overall VAC treatment but second cycle treatment was only required in 1 patient $(5 \%)$. This may be related to a more efficient induction of granulation tissue and space obliteration of the chest cavity that can be obtained by VAC because of the 8-fold more negative pressure applied. Another advantage of the VAC system is its easy translation in any hospital because of its user-friendliness and widespread commercial availability.

Some authors have expressed concern regarding the safety of VAC treatment within postpneumonectomy cavities. ${ }^{17}$ To overcome potential complications related to direct application of VAC suction on mediastinal structures, mediastinal and bronchial stump reinforcement by use of intrathoracic muscle transposition (ie, latissimus dorsi, serratus anterior, or pectoralis major) was performed in all patients. In addition, the cavity was packed with sterile 
dry gauzes before applying a first polyurethane foam within the chest cavity to avoid direct contact of the VAC device with the mediastinum. Taking these precautions, we did not observe any injury of mediastinal organs or great vessels. In addition, muscle transfer participated in the chest cavity obliteration process.

In this study, all VAC dressing changes were performed under general anesthesia, which made the VAC changes easy and well tolerated by patients. Different studies have recently tested the application of intrathoracic VAC therapy on an ambulatory base through an open thoracic window. ${ }^{14,17}$ However in these reports, postpneumonectomy situations were excluded. Moreover, several of these patients required plastic chest wall reconstruction for thoracostomy closure because of chronic desmoplastic tissue retraction at the thoracic window site. In addition, VAC therapy was discontinued in several patients because of side effects, including hypotension and chest pain and dressing changes might be cumbersome through a narrow thoracostomy. In contrast, VAC dressing changes under general anesthesia enabled a comfortable inspection of the chest cavity, including the mediastinum, and reclosure of the skin by several stitches to prevent tissue retraction. In fact, all patients in our series underwent an uncomplicated thoracic window closure at the end of VAC strategy without the need of plastic reconstructions by use of flaps.

At the time of thoracostomy closure, only $53 \%$ of the assessed foams revealed negative microbiologic findings. However, careful attention was paid to the presence of granulation tissue coverage of the entire chest cavity and mediastinum before definitive chest closure, indicating that granulation tissue coverage is probably more important for the determination of the timing for chest closure than negative microbiologic findings.

\section{CONCLUSIONS}

Intrathoracic VAC therapy is a safe, well-tolerated, and effective treatment for the management of infected postpneumonectomy cavities, provided it is performed in the context of properly applied surgical principles while avoiding a direct contact of the VAC foam with the mediastinum by interposition of sterile gauzes.

\section{References}

1. Schneiter D, Cassina P, Korom S, Inci I, Al-Abdullatief M, Dutly A, et al. Accelerated treatment for early and late postpneumonectomy empyema. Ann Thorac Surg. 2001;72:1668-72.

2. Schneiter D, Grodzki T, Lardinois D, Kestenholz PB, Wojcik J, Kubisa B, et al. Accelerated treatment of postpneumonectomy empyema: a binational long-term study. J Thorac Cardiovasc Surg. 2008;136:179-85.

3. Argenta LC, Morykwas MJ. Vacuum-assisted closure: a new method for wound control and treatment: clinical experience. Ann Plastic Surg. 1997;38:563-76; discussion 577.
4. Banwell PE, Musgrave M. Topical negative pressure therapy: mechanisms and indications. Int Wound J. 2004;1:95-106.

5. Hardwicke J, Paterson P. A role for vacuum-assisted closure in lower limb trauma: a proposed algorithm. Int J Lower Extrem Wounds. 2006; 5:101-4.

6. Perez D, Wildi S, Demartines N, Bramkamp M, Koehler C, Clavien PA. Prospective evaluation of vacuum-assisted closure in abdominal compartment syndrome and severe abdominal sepsis. J Am Coll Surg. 2007;205: 586-92.

7. Schintler M, Marschitz I, Trop M. The use of topical negative pressure in a paediatric patient with extensive burns. Burns. 2005;31:1050-3.

8. Assmann A, Boeken U, Feindt P, Schurr P, Akhyari P, Lichtenberg A. Vacuum-assisted wound closure is superior to primary rewiring in patients with deep sternal wound infection. Thorac Cardiovasc Surg. 2011;59: 25-9.

9. Groetzner J, Holzer M, Stockhausen D, Tchashin I, Altmayer M, Graba M, et al. Intrathoracic application of vacuum wound therapy following thoracic surgery. Thorac Cardiovasc Surg. 2009;57:417-20.

10. Schimmer C, Sommer SP, Bensch M, Elert O, Leyh R. Management of poststernotomy mediastinitis: experience and results of different therapy modalities. Thorac Cardiovasc Surg. 2008;56:200-4.

11. Hunter JE, Teot L, Horch R, Banwell PE. Evidence-based medicine: vacuum-assisted closure in wound care management. Int Wound J. 2007;4: 256-69.

12. Saadi A, Perentes JY, Gonzalez M, Tempia AC, Wang Y, Demartines N, et al. Vacuum-assisted closure device: a useful tool in the management of severe intrathoracic infections. Ann Thorac Surg. 2011;91:1582-9.

13. Aru GM, Jew NB, Tribble CG, Merrill WH. Intrathoracic vacuum-assisted management of persistent and infected pleural spaces. Ann Thorac Surg. 2010; 90:266-70.

14. Palmen M, van Breugel HN, Geskes GG, van Belle A, Swennen JM, Drijkoningen $\mathrm{AH}$, et al. Open window thoracostomy treatment of empyema is accelerated by vacuum-assisted closure. Ann Thorac Surg. 2009; 88:1131-6.

15. Passera E, Guanella G, Meroni A, Chiesa G, Rizzi A, Rocco G. Amplatzer device and vacuum-assisted closure therapy to treat a thoracic empyema with bronchopleural fistula. Ann Thorac Surg. 2011;92:e23-5.

16. Varker KA, Ng T. Management of empyema cavity with the vacuum-assisted closure device. Ann Thorac Surg. 2006;81:723-5.

17. Rocco G, Cecere C, La Rocca A, Martucci N, Salvi R, Passera E, et al. Caveats in using vacuum-assisted closure for post-pneumonectomy empyema. Eur J Cardiothorac Surg. 2012;41:1069-71.

18. Bischoff M, Beck A, Frei P, Bischoff G. Pharmacokinetics of cefuroxime in traumatic wound secretion and antibacterial activity under vacuum therapy. J Chemother. 2010;22:92-7.

19. Meyer AJ, Krueger T, Lepori D, Dusmet M, Aubert JD, Pasche P, et al. Closure of large intrathoracic airway defects using extrathoracic muscle flaps. Ann Thorac Surg. 2004;77:397-404; discussion 405.

20. Widmer MK, Krueger T, Lardinois D, Banic A, Ris HB. A comparative evaluation of intrathoracic latissimus dorsi and serratus anterior muscle transposition. Eur J Cardiothorac Surg. 2000;18:435-9.

21. Gharagozloo F, Margolis M, Facktor M, Tempesta B, Najam F. Postpneumonectomy and postlobectomy empyema. Thorac Surg Clin. 2006; 16:215-22.

22. Liberman M, Cassivi SD. Bronchial stump dehiscence: update on prevention and management. Semin Thorac Cardiovasc Surg. 2007;19:366-73.

23. Wain JC. Management of late postpneumonectomy empyema and bronchopleural fistula. Chest Surg Clin North Am. 1996;6:529-41.

24. Pairolero PC, Arnold PG, Trastek VF, Meland NB, Kay PP. Postpneumonectomy empyema. The role of intrathoracic muscle transposition. J Thorac Cardiovasc Surg. 1990;99:958-66; discussion 966.

25. Webster J, Scuffham P, Sherriff KL, Stankiewicz M, Chaboyer WP. Negative pressure wound therapy for skin grafts and surgical wounds healing by primary intention. Cochrane Database Syst Rev. 2012;CD009261.

26. Zaheer S, Allen MS, Cassivi SD, Nichols FC III, Johnson CH, Deschamps C, et al. Postpneumonectomy empyema: results after the Clagett procedure. Ann Thorac Surg. 2006;82:279-86; discussion 286. 